\title{
¿Seesawing of Winter Temperature Extremes between East Asia and North America
}

\author{
Mi-Kyung Sung, ${ }^{\mathrm{a}}$ Seok-Woo Son, ${ }^{\mathrm{b}}$ Changhyun Yoo, ${ }^{\mathrm{c}}$ JAeyoung Hwang, ${ }^{\mathrm{b}}$ And SoOn-IL AN ${ }^{\mathrm{a}}$ \\ ${ }^{\text {a } Y o n s e i ~ U n i v e r s i t y, ~ S e o u l, ~ S o u t h ~ K o r e a ~}$ \\ ${ }^{\mathrm{b}}$ Seoul National University, Seoul, South Korea \\ ${ }^{\mathrm{c}}$ Ewha Womans University, Seoul, South Korea
}

(Manuscript received 10 October 2020, in final form 12 January 2021)

\begin{abstract}
In recent winters, there have been repeated observations of extreme warm and cold spells in the midlatitude countries. This has evoked questions regarding how winter temperature extremes are induced. In this study, we demonstrate that abnormally warm winter weather in East Asia can drive the onset of extremely cold weather in North America approximately one week forward. These seesawing extremes across the basin are mediated by the North Pacific Oscillation (NPO), one of the recurrent atmospheric patterns over the North Pacific. Budget analysis of the quasigeostrophic geopotential tendency equation shows that intense thermal advection over East Asia is able to trigger the growth of the NPO. Vorticity fluxes associated with the upper-level stationary trough then strengthen and maintain the NPO against thermal damping following the onset of the NPO. Differential diabatic heating accompanied by changes in circulation also positively contribute to the growth and maintenance of the NPO. These results imply that recurrent cold extremes, seemingly contrary to global warming, may be an inherent feature resulting from strengthening warm extremes.
\end{abstract}

KEYWORDS: North Pacific Oscillation; Cold air surges; Extreme events

\section{Introduction}

With an increase in the global mean temperature, unseasonable warm spells have become more frequent in recent winters (Ma et al. 2018; Guirguis et al. 2011; Morak et al. 2013). Record-breaking cold spells have also been frequently observed in continents of the Northern Hemisphere (Kug et al. 2015; Johnson et al. 2018; Wolter et al. 2015). For instance, the warmest average temperature for the contiguous United States in December was recorded in 2015. A few years later, the second and third warmest periods for February were observed in 2017 and 2018, respectively (NOAA National Climate Report 2020). In contrast, in the U.S. Midwest, the top 10 recorded coldest winter temperatures occurred in 2013/14, and the all-time lowest temperature was registered in January 2018.

Recurrent cold extremes, which appear to contradict the overall global warming trend, have highlighted the unprecedented reduction in Arctic sea ice. A series of studies have proposed that Arctic warming leads to a contrasting cooling over the continents (Honda et al. 2009; Mori et al. 2014; Kug et al. 2015; Cohen et al. 2018). On the other hand, other studies have suggested that the warming trend in the tropical sea surface temperature is responsible for fluctuating winter temperatures (Hartmann 2014; Palmer 2014; Watson et al. 2016; Sung et al. 2019). This has been attributed to elevated sea surface temperatures in the western tropical Pacific. It is speculated that a consequent Rossby wave train propagates into the extratropics leading to temperature extremes or changes in the growth of dominant climate modes to strengthen their influence (Watson et al. 2016; Sung et al. 2019). Although there have been considerable advances in understanding the mechanisms underpinning winter extremes, the Arctic-midlatitude teleconnection is not yet fully

¿ Denotes content that is immediately available upon publication as open access.

Corresponding author: Soon-Il An, sian@yonsei.ac.kr understood, nor is the tropical connection. This requires further physical and dynamical investigations into these winter extremes (McCusker et al. 2016; Francis 2017; Blackport et al. 2019; Cohen et al. 2020).

In this context, attention should be directed to recent studies of temperature extremes in North America (NA), attributed to the North Pacific Oscillation (NPO) (Furtado et al. 2012; Lee et al. 2015; Di Lorenzo and Mantua 2016; Sung et al. 2019). The NPO, which is also known to be the lower tropospheric footprint of the western Pacific pattern, is the second dominant atmospheric mode over the North Pacific, succeeding the Pacific-North American (PNA) pattern (Wallace and Gutzler 1981; Rogers 1981; Linkin and Nigam 2008; Feldstein and Franzke 2017). It was revealed that both warm and cold temperature extremes in NA could result from the phase flip of the NPO (Sung et al. 2019) that accompanies a pressure trough or ridge over Alaska (Linkin and Nigam 2008; Walker and Bliss 1932; Rogers 1981). Notably, the NPO is known to be significantly correlated with the East Asian winter monsoon (EAWM) as well, although the physical mechanism remains obscure (Wang et al. 2007; Pak et al. 2014). These studies suggest that the EAWM-NPO correlation is not stationary but rather has changed over the decades; the correlation has increased since the early 2000s with the reamplification of the EAWM (Pak et al. 2014; Wang and Chen 2014). This is in good agreement with the period during which the downstream influence of the NPO on the NA winter temperature became influential (Sung et al. 2019).

Based on this context, we investigate the growth mechanism of the NPO and its relation to upstream circulation over East Asia (EA). Considering the intrinsic time scale of the NPO, which is approximately two weeks (Feldstein 2000), we traced the daily evolution of the NPO to examine its driving processes. Recently, it has been demonstrated that temperature fluctuations in NA are significantly correlated with preceding temperature anomalies over Siberia at the subseasonal time scale, highlighting advantages to subseasonal forecasts (Lin 2018). Our analysis corroborates this intercontinental link for extreme temperature events, mediated by 

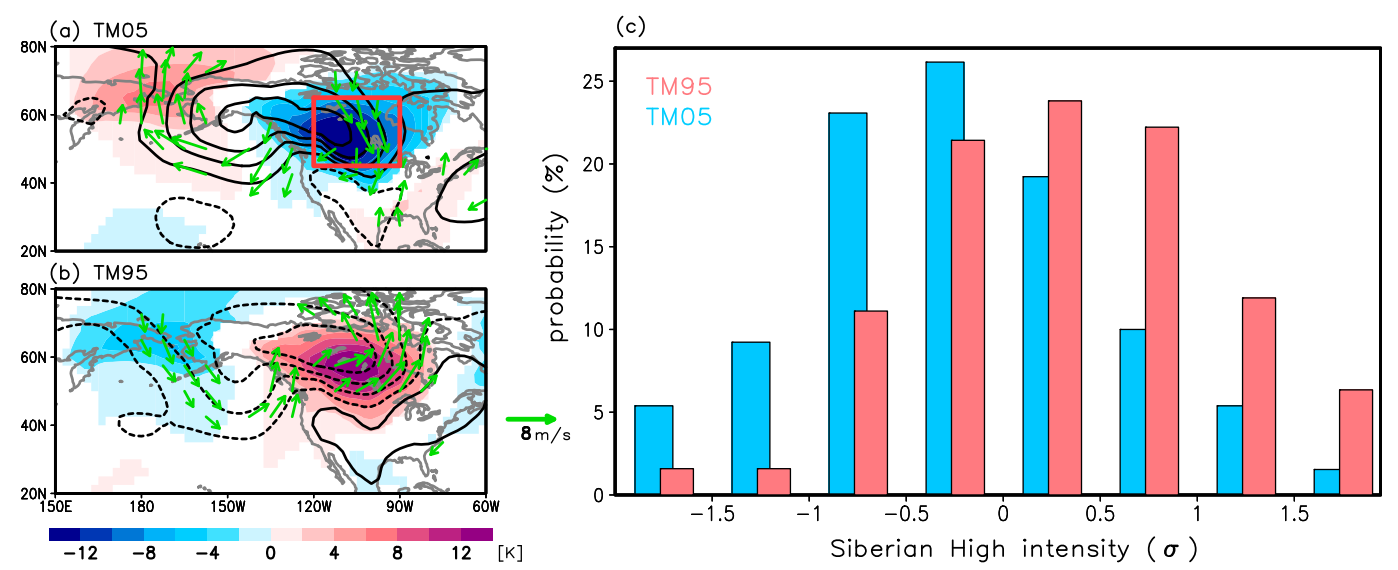

FIG. 1. (a),(b) Sea level pressure (SLP) anomalies (contour) that introduce cold and warm extremes in NA, defined by the 5th (TM05) and 95th percentiles (TM95), respectively, for daily surface air temperature (shading) over the red-boxed region. Vectors denote a wind anomaly stronger than $3 \mathrm{~m} \mathrm{~s}^{-1}$ at the $925-\mathrm{hPa}$ level. For shading and vectors, only statistically significant values at the $95 \%$ confidence level are displayed. (c) Probability distribution of TM05 (blue bars) and TM95 (red bars) as a function of the Siberian high (SH) intensity (averaged over a lag from -9 to -7 days) prior to the occurrence of temperature extremes in North America (NA).

the NPO, and also elucidates the underlying dynamics based on budget analysis of the quasigeostrophic geopotential tendency equation (Holton 2004). The results suggest that there are implications regarding how and why the probabilities of warm and cold extremes increase with the acceleration of global warming. Last, we briefly discuss the hypothesis that Arctic warming exerts subseasonal influence on midlatitude temperature extremes, which may be exaggerated or neglected in some cases.

\section{Data and methods}

\section{a. Data used and definitions}

The JRA-55 6-hourly reanalysis data (with $2.5^{\circ} \times 2.5^{\circ}$ resolution) were used after being integrated into daily mean, focusing on wintertime variability (November to March; NDJFM for 1958-2018) (Kobayashi et al. 2015). The daily anomaly of each variable was computed by subtracting the seasonal cycle at each grid point, which was obtained from the first three harmonics of the calendar mean for each day, omitting 29 February in leap years. Although we examined the daily evolution of the NPO, the spatial structure of the NPO was defined by the second leading empirical orthogonal function (EOF2) (Linkin and Nigam 2008) of the monthly sea level pressure (SLP) anomaly over the North Pacific $\left(110^{\circ} \mathrm{E}-120^{\circ} \mathrm{W}, 20^{\circ}-70^{\circ} \mathrm{N}\right)$ in November-March (NDJFM). This monthly EOF2 explained $19.4 \%$ of the total variance following the first leading EOF, which accounted for $37.7 \%$ variance, consistent with the earlier study. The daily NPO index was then computed by projecting the EOF2 pattern onto the daily SLP anomaly over the analysis domain. A positive NPO (+NPO) event was set when the NPO index exceeded $1 \sigma$ for more than three consecutive days. Similarly, a negative NPO ( $-\mathrm{NPO}$ ) event was set when the NPO index fell below $-1 \sigma$. The first day that the threshold was exceeded was defined as the onset day. To isolate the growth feature of the NPO event such that it was not disturbed by an antecedent event, we only considered events that were distinctly separate from preceding events by being recovered to normal conditions (i.e., $-0.5 \sigma<\mathrm{NPO}<0.5 \sigma$ ); this yielded 168 positive and 165 negative NPO events.
A strengthened or weakened Siberian high $(\mathrm{SH})$ event was defined by employing a $\pm 1.5 \sigma$ threshold to the $\mathrm{SH}$ index. This was defined by averaging the SLP anomaly over the $90^{\circ}-130^{\circ} \mathrm{E}$ and $40^{\circ}-65^{\circ} \mathrm{N}$ regions. Similar to the NPO, $\mathrm{SH}$ events were set when the $\mathrm{SH}$ index exceeded thresholds for more than three consecutive days when unperturbed by other events. We adopted strict thresholds to detect excessively strong or weak SH events that introduce severe cold or warm surges to EA; as such, we identified 83 strong and 64 weak SH events. We note that lower threshold values also provide overall consistent results (not shown).

Temperature anomalies over EA and NA were represented by the area average over $100^{\circ} \mathrm{E}-130^{\circ} \mathrm{W}$ and $30^{\circ}-50^{\circ} \mathrm{N}$ and over $90^{\circ}-$ $120^{\circ} \mathrm{W}$ and $45^{\circ}-65^{\circ} \mathrm{N}$, respectively. To define extreme temperature events in central NA (the boxed region in Fig. 1a), the first day when the temperature went below $5 \%$ or above $95 \%$ during the winter (NDJFM) was set as the TM05 or TM95 event, respectively. Once daily temperature exceeded these thresholds, the subsequent cold or warm extreme event was probed only when the daily temperature recovered to a value above $-0.5 \sigma$ or below $0.5 \sigma$, respectively. This resulted in a total of 130 TM05 and 126 TM95 events over the analysis period. To determine the statistical significance, we adopted Welch's $t$ test, which is used to compare the means of two independent samples with unequal variances (Welch 1938).

\section{b. Quasigeostrophic geopotential tendency equation}

To quantify the dynamical effect of preceding perturbations in EA with NPO development, the quasigeostrophic geopotential tendency equation (Holton 2004; Lau and Holopainen 1984; Hwang et al. 2020) was utilized:

$$
\begin{aligned}
{\left[\nabla^{2}+\frac{\partial}{\partial p}\left(\frac{f_{0}^{2}}{\sigma_{s}} \frac{\partial}{\partial p}\right)\right] \frac{\partial \phi}{\partial t}=} & -f_{0} \nabla \cdot[\mathbf{V}(\zeta+f)]+\frac{\partial}{\partial p}\left(\frac{f_{0}^{2}}{\sigma_{s}} \frac{R}{P} \nabla \cdot \mathbf{V} T\right) \\
& -\frac{\partial}{\partial p}\left(\frac{f_{0}^{2}}{\sigma_{s}} \frac{R}{P} \frac{J}{c_{p}}\right),
\end{aligned}
$$


where $\phi$ is the geopotential (geopotential height $\equiv \phi / g_{0}$, where $g_{0}$ is gravitational acceleration $\left.=9.8 \mathrm{~m} \mathrm{~s}^{-2}\right) ; \mathbf{V}$ is the horizontal wind vector; $\zeta$ and $f$ are the relative and planetary vorticities, respectively $\left(f_{0}\right.$ is $f$ at $\left.45^{\circ} \mathrm{N}\right) ; p$ is pressure $\left(p_{0}\right.$ is the reference pressure of $1000 \mathrm{hPa}$ ); $R$ is the gas constant for dry air; and $c_{p}$ is the specific heat of dry air at constant pressure. The static stability parameter, $\sigma_{s}\left[\equiv-(R / P)\left(p / p_{0}\right)^{R / c_{p}}\left(\partial \theta_{s} / \partial p\right)\right]$, was estimated using the Northern Hemisphere mean potential temperature $\theta_{s}(p)$. Note that, unlike in the conventional quasigeostrophic equation, the diabatic heating term $(J)$ was included. This term was estimated from the heating rates of longwave radiation, shortwave radiation, convection, large-scale condensation, and vertical diffusion as provided by model forecast fields of JRA-55. Instead of the geostrophic wind, the full wind was utilized to compute horizontal advection, as it yields more realistic results compared with observations (Hwang et al. 2020).

The geopotential tendency at $850 \mathrm{hPa}$ was derived by inverting the above equation. This level was selected to consider the influence of strong thermal anomalies caused by extreme cold or warm surges in EA on downstream atmospheric circulations. Although the thermal influence near the surface is stronger than the one at $850 \mathrm{hPa}$, the former is less reliable because of the boundary condition issue when computing the inversion. The influence of thermal anomalies was assessed by the second forcing term of the equation, that is, temperature flux forcing $F^{T}$, which comprises differential temperature advection $F_{\text {adv }}^{T}$ and the adiabatic warming/cooling due to vertical stretching associated with the divergent secondary circulation $F_{\text {stretch }}^{T}$ :

$$
\begin{aligned}
F^{T} & =F_{\text {adv }}^{T}+F_{\text {stretch }}^{T}, \\
F_{\text {adv }}^{T} & =\frac{\partial}{\partial p}\left(\frac{f_{0}^{2}}{\sigma_{s}} \frac{R}{P} \mathbf{V} \cdot \nabla T\right), \\
F_{\text {stretch }}^{T} & =\frac{\partial}{\partial p}\left(\frac{f_{0}^{2}}{\sigma_{s}} \frac{R}{P} T \nabla \cdot \mathbf{V}\right)=\frac{\partial}{\partial p}\left(\frac{f_{0}^{2}}{\sigma_{s}} \frac{\partial \Phi}{\partial p} \frac{\partial \omega}{\partial p}\right) .
\end{aligned}
$$

The development of strong cold or warm surges in EA is usually accompanied by anomalous expansion or shrinkage of the upper-level stationary trough (i.e., East Asian trough) (Wang et al. 2009; Nakamura et al. 2010; Takaya and Nakamura 2005; Song et al. 2016). Therefore, it is essential to consider the influence of changes in upper-level circulations, which may be resolved by the first forcing term; vorticity flux forcing $F^{\text {Vort }}$. This term can be decomposed as

$$
\begin{aligned}
F^{\mathrm{Vort}} & =F_{\mathrm{adv}}^{\mathrm{Vort}}+F_{\mathrm{stretch}}^{\mathrm{Vort}}, \\
F_{\mathrm{adv}}^{\mathrm{Vort}} & =-f_{0} \mathbf{V} \cdot \nabla(\zeta+f), \\
F_{\text {stretch }}^{\mathrm{Vort}} & =-f_{0}(\zeta+f) \nabla \cdot \mathbf{V}=f_{0}(\zeta+f) \frac{\partial \omega}{\partial p},
\end{aligned}
$$

The vorticity advection $F_{\text {adv }}^{\text {Vort }}$ typically acts to propagate a disturbance horizontally rather than changing the strength. On the other hand, the vortex stretching by ageostrophic vertical circulation $F_{\text {stretch }}^{\text {Vort }}$ modifies the effects of vorticity advection and amplifies a disturbance (Holton 2004). We also considered the effect of diabatic heating, as cold air that surges into the EA coastal region is able to promote the release of considerable amounts of latent and sensible heat from the ocean surface.

To solve the equation, a successive overrelaxation method was employed in wavenumber-frequency space. For the surface boundary condition, a Neumann boundary condition (Lau and Holopainen 1984) was applied by considering the thermodynamic equation (Hwang et al. 2020). Although not shown, the overall results were nonsensitive to the details of surface boundary conditions. The estimated tendency was composited for NPO events to examine daily growth by the forcing components. Then, for the comparison of relative contributions of each forcing, the composite results were projected onto the mature NPO pattern at $850 \mathrm{hPa}$ (i.e., geopotential height anomalies averaged from the onset to a lag of +4 days). The projection was applied to the North Pacific domain $\left(110^{\circ} \mathrm{E}-120^{\circ} \mathrm{W}, 20^{\circ}-70^{\circ} \mathrm{N}\right)$, the same as the region used to define the NPO, which provided the temporal evolution of each term.

\section{Results}

\section{a. "Seesawing extremes" across the North Pacific}

Abnormally cold or warm winter weather in NA is frequently induced by anomalous anticyclonic or cyclonic circulation centered over Alaska (Fig. 1). As the surface anticyclone extends toward inland NA (contours in Fig. 1a), a cold blast sweeps across the central and eastern NA (blue shading). Cyclonic circulation brings an anomalous southwesterly wind, resulting in unusually warm winter weather (Fig. 1b). The probability of these cold and warm winter extremes is altered by antecedent conditions of the $\mathrm{SH}$ across the North Pacific (Fig. 1c). Interestingly, the probability of NA warm spells, defined as the daily temperature anomalies above the 95th percentile (TM95) over the 1958-2018 period, markedly increases when preceded by an abnormally strong $\mathrm{SH}$ approximately one week prior (red bars). Likewise, NA cold spells, defined as daily temperature anomalies below the 5th percentile (TM05), preferably occur when the $\mathrm{SH}$ is weak (blue bars). Quantitatively, approximately $40 \%$ of NA warm extremes are preceded by an anomalously strong $\mathrm{SH}(\mathrm{SH}>0.5 \sigma)$. This percentage is more than twice that representing those preceded by an anomalously weak $\mathrm{SH}(14 \%$ for $\mathrm{SH}<-0.5 \sigma)$. The correlation coefficients between the onset-day temperatures of TM05 and TM95 events and the preceding SH intensity (i.e., SH index averaged from lag -9 to -7 days before the onset of TM05 and TM95 events) are 0.29 and 0.36, respectively, which are statistically significant at $99 \%$ confidence level. These results indicate that weather conditions in EA, primarily governed by SH during winter (Takaya and Nakamura 2005; Joung and Hitchman 1982), are intimately linked with extreme events in NA.

To understand the underlying physical mechanism, we traced the growth of typical circulation patterns that introduce extreme weather in NA (Fig. 2), which are projected onto the NPO (Lee et al. 2015; Linkin and Nigam 2008). As shown by the third row panels in Fig. 2, the NPO is characterized as a basinwide north-south oscillation of SLP over the North Pacific (Walker and Bliss 1932). In contrast to the southern lobe of the NPO, which is comparatively weaker, the northern 
(a) +NPO
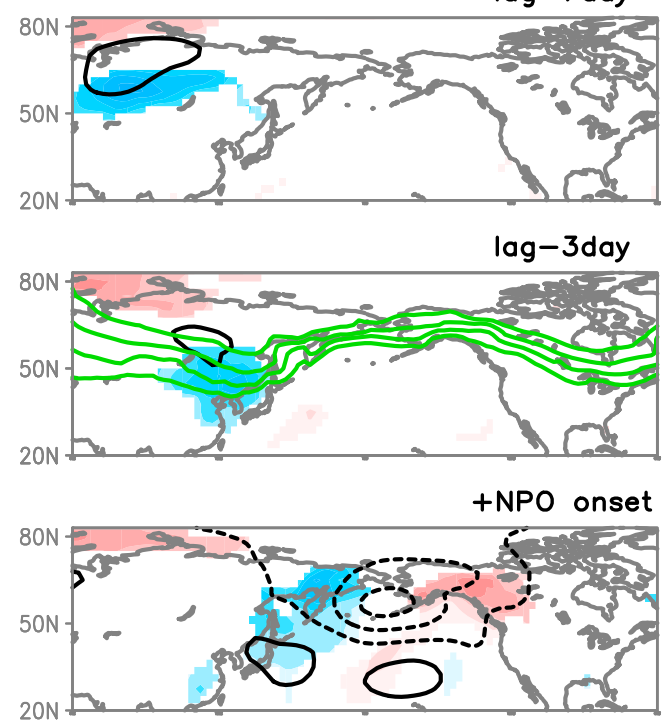

lag+3day

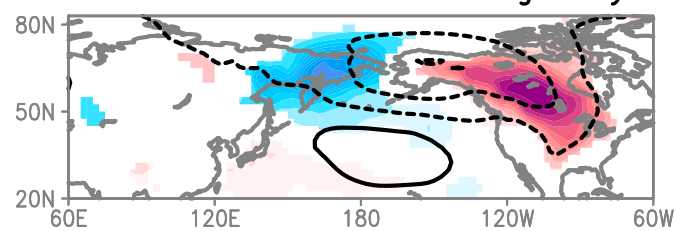

(b) $-\mathrm{NPO}$
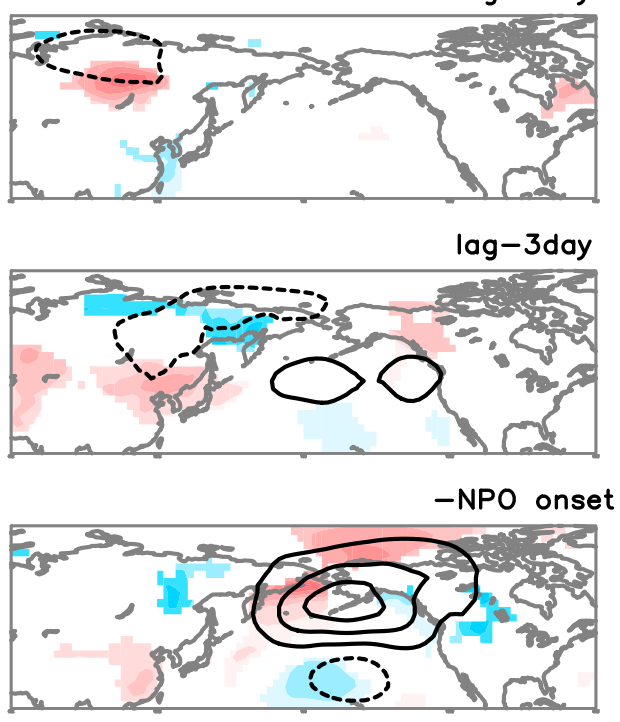

lag+3day

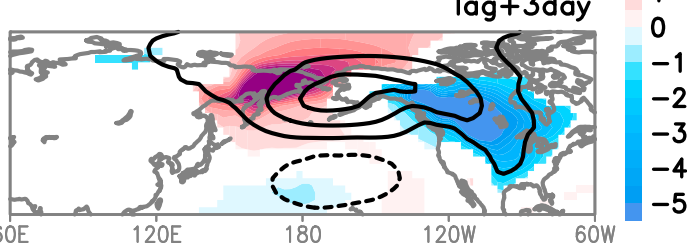

FIG. 2. Spatiotemporal evolution of surface air temperature (shaded for statistically significant values at the $95 \%$ confidence level) and SLP anomalies (contours with 3-hPa intervals omitting the zero line) during (a) + NPO and (b) - NPO events. The solid (dashed) line denotes positive (negative) pressure anomalies. Green lines in (a) denote isotherms of climatological potential temperature.

lobe near Alaska tends to exhibit a stronger intensity. When the northern lobe is cyclonic [positive phase of the NPO (+NPO)], it accompanies anomalously warm weather in the central NA a few days later (Fig. 2a). Similarly, when the northern lobe is anticyclonic [negative phase of the NPO (-NPO)], it is followed by anomalously cold weather in NA (Fig. 2b) (Rogers 1981; Linkin and Nigam 2008). The spatiotemporal evolution of the NPO shows that, approximately 10 days prior to the appearance of NA temperature anomalies, opposite-signed temperature anomalies are evident over Siberia (top panels, Fig. 2). Specifically, warm anomalies in central NA are preceded by prominent cold anomalies over EA, while a +NPO grows. The same type of relation, with an opposite sign of temperature anomalies, was evident during a $-\mathrm{NPO}$. The results were not much sensitive to the choice of the threshold values for NPO events. When the threshold is increased from $0.5 \sigma$ to $1.0 \sigma$, and to $1.5 \sigma$, the temperature anomaly associated with the NPO systematically increases without much change in the spatial distribution (not shown).

Notably, precursor temperature anomalies over Siberia (lag of -7 days) gradually move from Siberia to EA along background isotherms (green contours in Fig. 2a). This southeastward displacement of temperature anomalies is closely related to the migration of the surface thermal Rossby wave that brings abnormal weather conditions to EA (Gill 1982; Sung et al. 2010; Takaya and Nakamura 2005). It is a general characteristic of the thermal
Rossby wave trapped near the surface to have a self-migrating tendency parallel to background isotherms (Fig. 3). Over Siberia, frigid, high-density air (blue shading) forms a high pressure center, and the associated anticyclonic circulation induces cold advection to the east (Hoskins et al. 1985). The resulting cold anomaly causes the high pressure center to extend and move eastward by itself, leading to the self-migration of the thermal Rossby wave (Takaya and Nakamura 2005). This process tends to continue, eventually causing a cold surge in EA a few days later (Fig. 3c). Essentially the same process occurs for the surface warm anomalies (red shading), bringing warm spells to EA. These characteristic behaviors of the thermal Rossby wave have been well captured by the anticyclonic or cyclonic centers confined below $850 \mathrm{hPa}$ in the vertical cross sections across the cold or warm surface anomalies (right columns).

The precursory signals over Siberia prior to the growth of the NPO suggests an inherent link between subseasonal fluctuations of temperature in NA and antecedent weather conditions in EA. This relation was also observed on a consistent basis when the SH excessively strengthens or weakens (Fig. 4). The strengthening SH, leading to a cold surge in EA (red curve in Fig. 4a), is generally followed by a warm spell in central NA approximately one week later (Fig. 4c). Figure 4b suggests that these changes are mediated by a +NPO. Likewise, the temporal evolution of the - NPO reaches its negative peak 

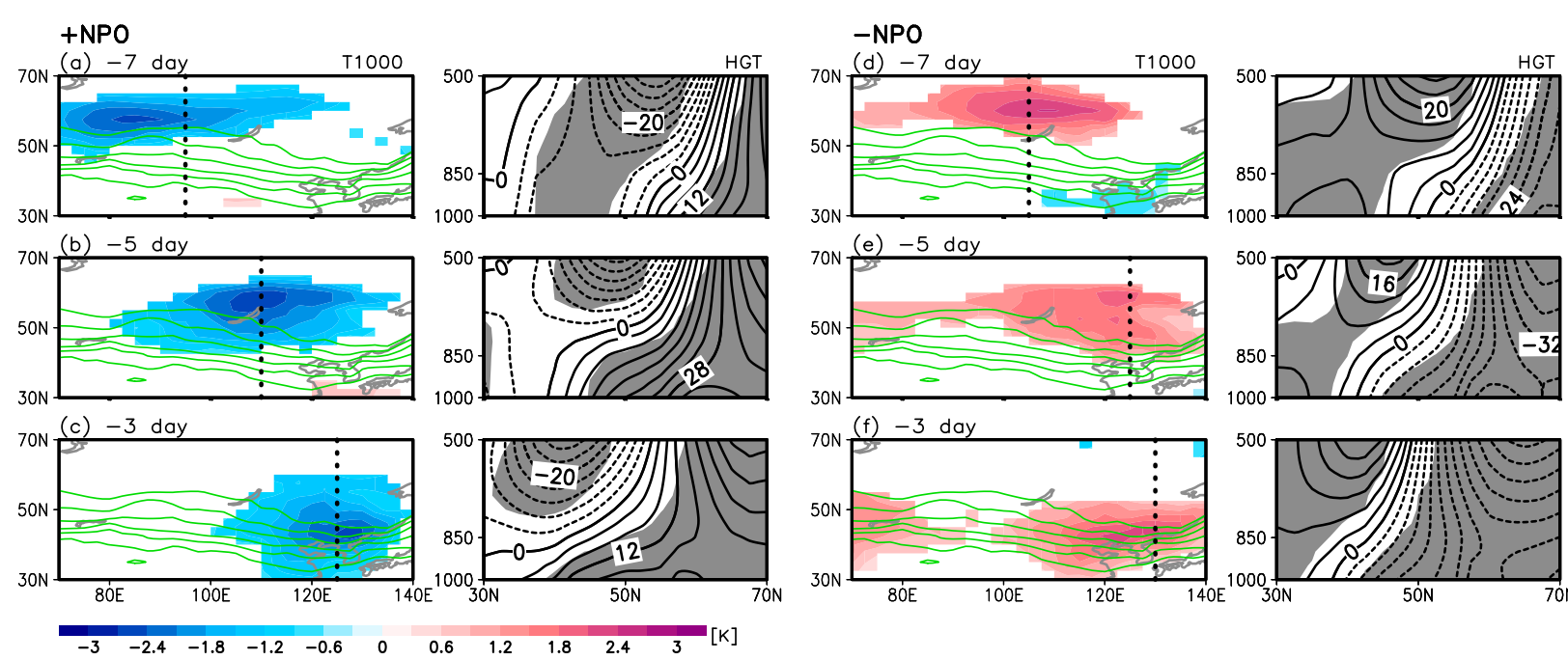

FIG. 3. (left) Daily evolution of 1000-hPa temperature anomalies (shading) prior to the onset of (a)-(c) + NPO and (d)-(f) - NPO events. The isotherms of climatological potential temperature are denoted by the green contours (3-K intervals starting from $264 \mathrm{~K}$ ). (right) Vertical cross section of geopotential height anomalies across the latitudinal range depicted by black dotted lines in the left panels (4-gpm intervals). The statistically significant values at the $95 \%$ confidence level are shaded.

approximately one week following the weakening of the $\mathrm{SH}$ (blue curve). While anomalous warming prevails over EA due to SH weakening, a - NPO begins to grow, whereby the NA ultimately experiences a cold spell one week later. The weaker magnitudes of temperature anomalies in NA compared to those in EA may be due to two aspects: 1) the NA temperature is determined by multiple factors in addition to the NPO, and 2) the growth of the NPO is influenced by other factors such as the position and strength of the Aleutian low over the North Pacific (Rogers 1981; Linkin and Nigam 2008). In section 3b, we elucidate how intense warm or cold anomalies over EA result in a descent or ascent of temperatures across the basin through the NPO.

\section{b. Mechanism underpinning seesawing extremes}

The growth mechanism underpinning cold surges has long been a topic of interest for researchers. On the other hand, the resultant changes in atmospheric circulation from cold surges has received less attention, despite them being accompanied by steep changes in the distributions of atmospheric mass and available potential energy. By employing the quasigeostrophic geopotential tendency equation (Holton 2004), we were able to investigate the atmospheric response to intense thermal phenomena over EA. Figure 5 illustrates the observed daily evolution tendency of the $850-\mathrm{hPa}$ geopotential height during the +NPO growth (i.e., forward difference between two consecutive days; contour), and highlights how this tendency is driven by three forcing components (shading). In terms of spatial distribution, the estimated tendency produced by the three contributing factors captures the observed tendencies remarkably well (Fig. 5a). This suggests that the NPO growth may be explained via the baroclinic framework, consistent with the conclusions of recent studies (Tanaka et al. 2016; Sung et al. 2020; Kim et al. 2021). The observed and estimated results show that a negative tendency appears over the EA coastal region at a lag of -4 days. It then grows toward the northern lobe of the +NPO. A positive counterpart also begins to grow over the Korean Peninsula at a lag of -3 days, concurrent with cold advection in this region (also see Fig. 3). Although the positive tendency assessed by all three forcing components appears at a lag of -3 days, it begins from a lag of -4 days as it is generated by the thermal forcing $F^{T}$ (Fig. 5b). This positive

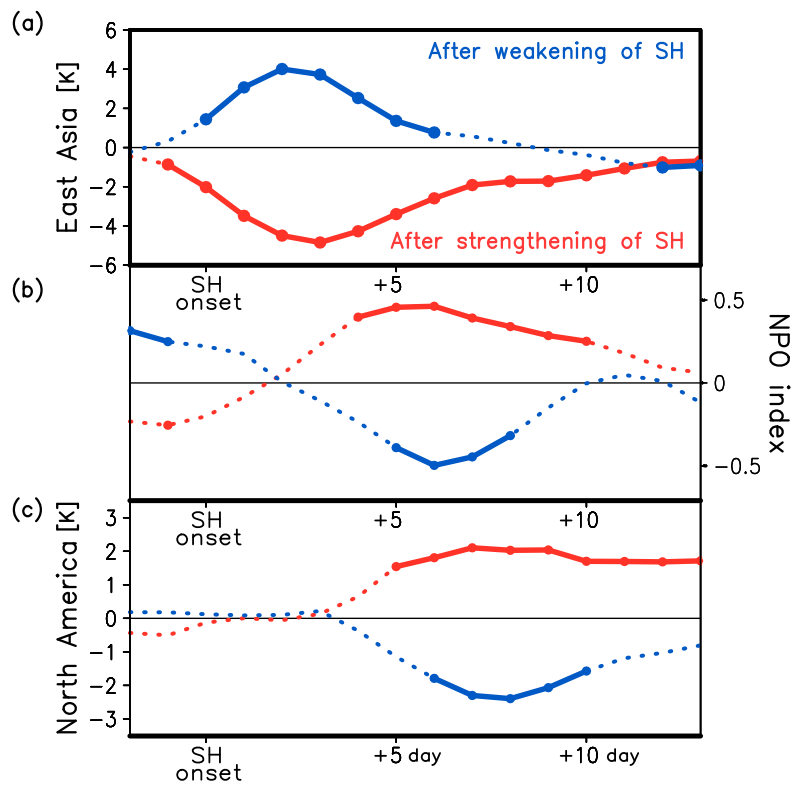

FIG. 4. Daily evolutions of (a) EA surface air temperature, (b) the NPO index, and (c) NA surface air temperature during the strengthening (red) and weakening (blue) of the SH. The statistically significant values at the $95 \%$ confidence level are denoted by solid lines. 
+NPO lag-4day

(a) all forcing

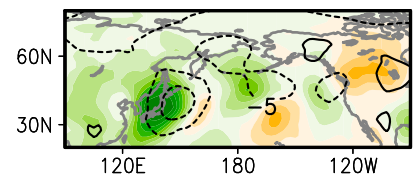

(b) $F^{T}$
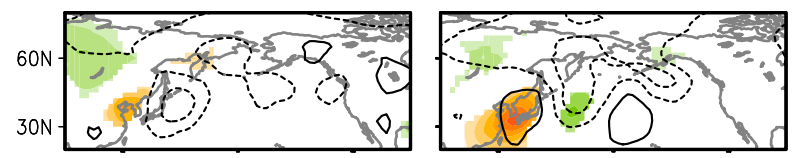

+NPO lag-2day

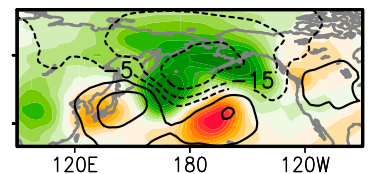

+NPO lag-1day

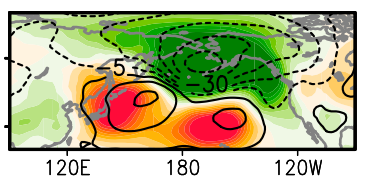

(c) $F^{\text {Vort }}$
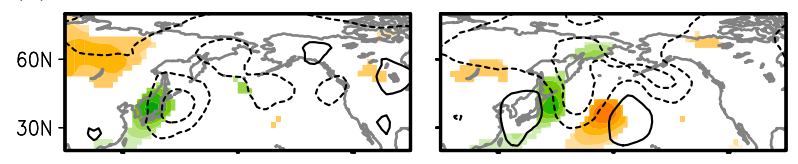

(d) $F^{\text {Diab }}$
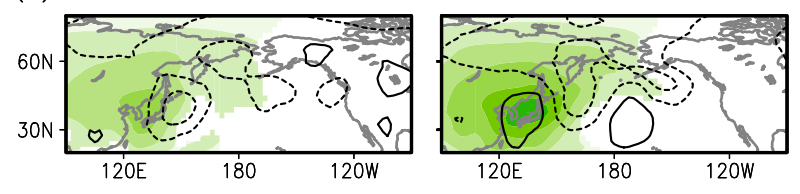
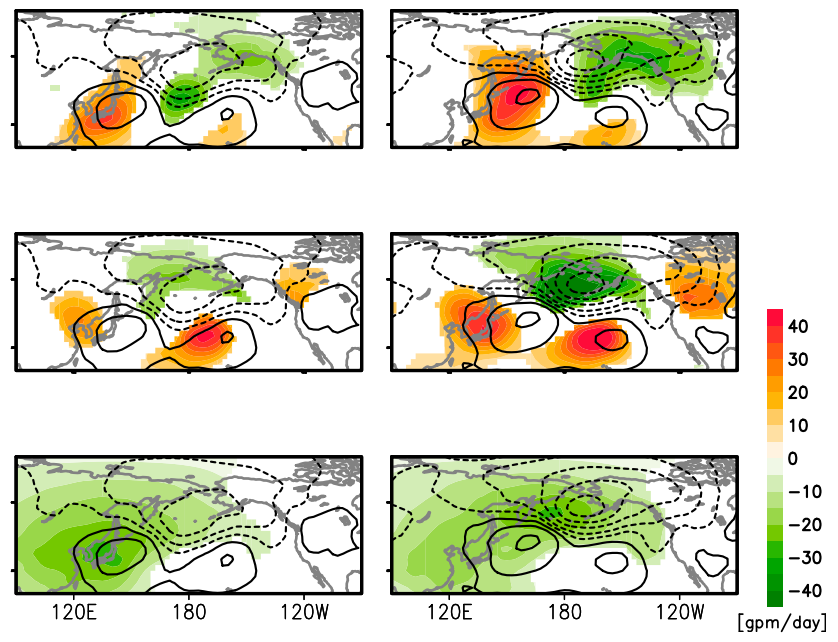

FIG. 5. Geopotential height tendency at $850 \mathrm{hPa}$ during +NPO events of observational data (contours) and estimated using the geopotential height tendency equation (shading) with (a) all forcing, (b) temperature fluxes $\left(F^{T}\right)$, (c) vorticity fluxes $\left(F^{\text {Vort }}\right)$, and (d) differential diabatic heating $\left(F^{\text {Diab }}\right)$ terms. Contours are drawn at $\pm 5, \pm 15, \pm 30, \pm 45$, and \pm 60 gpm day $^{-1}$. In (b)-(d), only statistically significant values at the $95 \%$ confidence level are shaded.

tendency generated by $F^{T}$ accounts for the observed tendency. As can be seen from Fig. 6a (shading), the thermal forcing is dominated by the differential temperature advection $F_{\text {adv }}^{T}$, while the influence of the vertical stretching $F_{\text {stretch }}^{T}$ accounts for a minor portion. The result suggests that the thermal effect plays a crucial role in initiating the + NPO. This tendency gradually strengthens over the North Pacific, interacting with other forcing terms.

In the meantime, the vorticity fluxes $F^{\text {Vort }}$ induce a negative geopotential height tendency over the North Pacific at a lag of -4 days (Fig. $5 \mathrm{c}$ ), providing an opposing tendency to that of the temperature fluxes. The negative tendency is supposedly due to the expanded East Asian trough; this is a result of the intense vertical interaction between the surface SH and upper tropospheric Rossby wave train, which is typically involved with cold air outbreaks in EA (Takaya and Nakamura 2005; Song et al. 2016). This strong vertical interaction converts the background available potential energy into the anomaly field, resulting in steep amplification of the SH and East Asian trough. These features are consistently observed in Fig. 7, which illustrates wave energy propagation from the Eurasia at a lag of -7 days to the North Pacific at a lag of -4 days [see vectors that denote the wave activity flux of Takaya and Nakamura (2001)]. The ensuing anomalies cause zonal expansion of the East Asian trough, as can be inferred from the cyclonic anomalies along the western and eastern flanks of the continental trough at a lag of -4 days. These upper tropospheric changes affect the lower tropospheric circulations and facilitate the growth of the NPO through vorticity fluxes (Fig. 5c), inducing dipolar tendencies in conjunction with thermal forcing.

Figure 6 shows that advection parts of the thermal and vorticity forcings (i.e., $F_{\text {adv }}^{T}$ and $F_{\text {adv }}^{\text {Vort }}$ ) dominate the growth of the NPO over the North Pacific (middle panels), while vertical stretching parts $\left(F_{\text {stretch }}^{T}\right.$ and $\left.F_{\text {stretch }}^{\text {Vort }}\right)$ act to oppose the changes (bottom panels). These results describe the intrinsic characteristics of the stretching terms that dilute the effects of advection terms to maintain geostrophic balance, facilitating vertical coupling between the lower and upper troposphere (Holton 2004). In addition to this, the influences of the stretching terms are notable near the jet stream (see blue contours that denote zonal wind climatology). Being favored by strong horizontal wind shear over the southern flank of the jet exit region, the stretching terms seem to positively contribute to the formation of southern circulation anomaly of $+\mathrm{NPO}$.

Returning to Fig. 5, unlike the influences of temperature and vorticity fluxes, diabatic heating only generates a negative tendency around the Korean Peninsula (Fig. 5d). The influence of this secondary heating often tends to be overlooked. However, quantitative budget analysis suggests a considerable role for this diabatic heating in NPO growth. The contribution of an EA cold surge on the + NPO was further quantified as a function of time by projecting the horizontal tendency onto the mature NPO pattern at $850 \mathrm{hPa}$ (Fig. 8). In the same manner, the observed tendency was also projected onto the NPO 


$$
+ \text { NPO (lag-1day) }
$$

(a) $F^{T}$

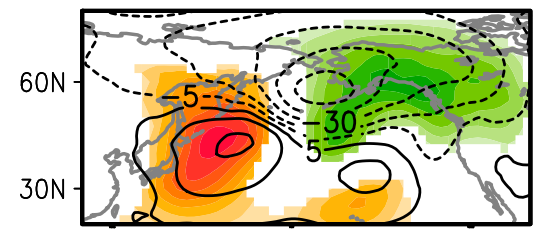

$F_{\mathrm{ddv}}^{T}$

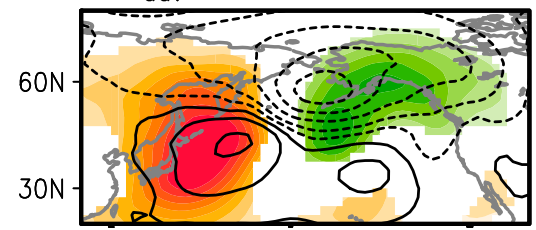

$\boldsymbol{F}^{T}{ }^{T}$

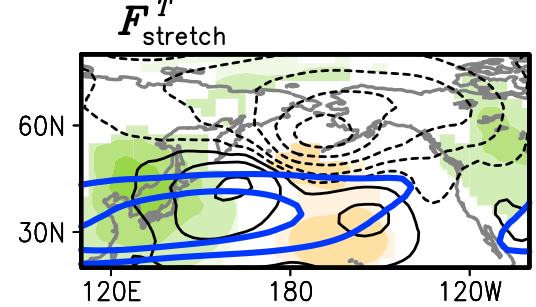

(b) $F^{\text {Vort }}$
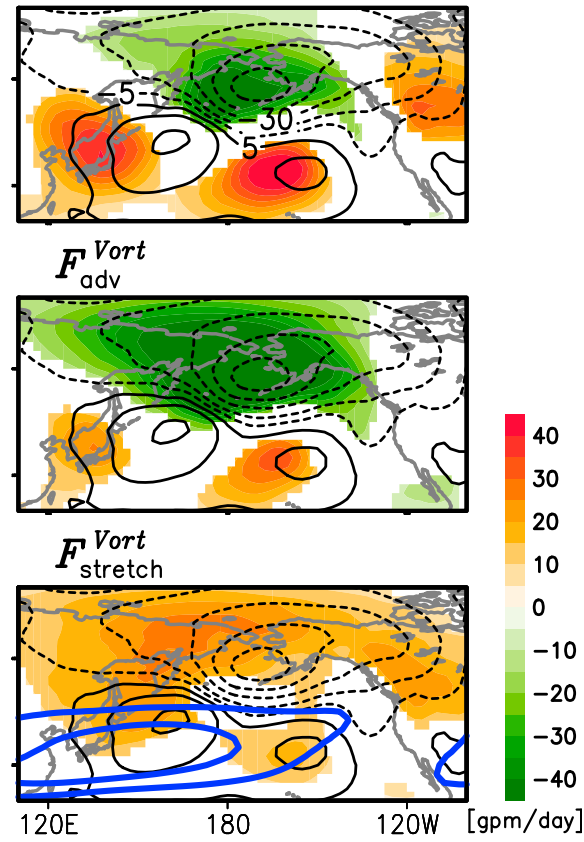

FIG. 6. Geopotential height tendency at $850 \mathrm{hPa}$ at lag -1 day for $+\mathrm{NPO}$ events: observation (contours) and the computed tendency (shading) from (a) temperature fluxes $\left(F^{T}\right)$ and (b) vorticity fluxes $\left(F^{\text {Vort }}\right)$. Middle and bottom panels display the values that correspond to horizontal advection (i.e., $F_{\text {adv }}^{T}$ and $F_{\text {adv }}^{\text {Vort }}$ ) and vertical stretching components (i.e., $F_{\text {stretch }}^{T}$ and $F_{\text {stretch }}^{\text {Vort }}$ ), respectively. Blue contours denote zonal wind climatology at $300 \mathrm{hPa}$ (NDJFM average drawn at 25 and $45 \mathrm{~m} \mathrm{~s}^{-1}$ ). Other details are as in Fig. 5.

pattern over the North Pacific domain to check the balance of the budget analysis (gray solid curve in Fig. 8). The observed tendency is positive until the onset day then switches the sign to negative. Compared to the observation, the combined influences of the three contributing factors (black curve) tend to overestimate the tendency during the decaying phase of the NPO, though their spatial distributions match well as shown in Fig. 5. Although not shown, the residues between the observed and estimated tendencies become much smaller in the midtroposphere, possibly indicating that they are partly associated with dynamical damping. It is speculated that small-scale turbulence that is not taken into account in the current analysis might contribute to the residues. This result suggests that the three forcing components account reasonably well for the growth of +NPO, although not for the decay.

Specifically, a geopotential height tendency by temperature fluxes (red curve) precedes an NPO, contributing positively to a + NPO growth prior to onset, as observed in the horizontal anomaly pattern. However, its contribution becomes negative after the onset day, leading to the decay of a +NPO. This clearly indicates that the overall life cycle of a $+\mathrm{NPO}$ is steered by thermal forcing. In contrast, a tendency due to the vorticity fluxes, reflecting the contribution of the upper-level trough, tends to maintain positive values throughout the life cycle of a + NPO. This indicates that a + NPO intensifies and persists through vertical coupling of the upper-level trough to surface anomalies. Given the results of Song et al. (2016), who elucidated the contribution of the synoptic transient eddies to the deepening of the East Asian trough attendant upon the outbreak of cold surges, within the vorticity forcing the influence of transient eddies might be included, as the abrupt changes in the background baroclinicity significantly modulate synoptic eddy characteristics. Diabatic heating, which shows a uniform sign of the forcing in the horizontal distribution, also positively contributes to the growth and maintenance of the NPO. These results reveal the intrinsic nature of NPO, which is steered by thermal processes over EA and is intensified by the interaction between the upper-level trough and surface anomalies over the North Pacific, as well as the diabatic heating induced by circulation changes.

These results are also true for -NPO (Fig. 8b); a positive tendency from anomalous heat fluxes precedes the NPO onset acting to trigger the growth of -NPO. The other two forces then follow to accelerate growth, similar to the +NPO processes. The weaker contribution of thermal forcing is presumably because of the smaller rate of vertical change for warm advection, in contrast to cold advection. Specifically, the intensity of the thermal forcing is proportional to the rate of vertical changes in temperature advection. The cold advection near the surface is capable of affecting the adjacent atmospheric circulation more efficiently as the atmosphere above the ocean is much warmer, although not for warm advection. Nevertheless, 
(a) $+\mathrm{NPO}$
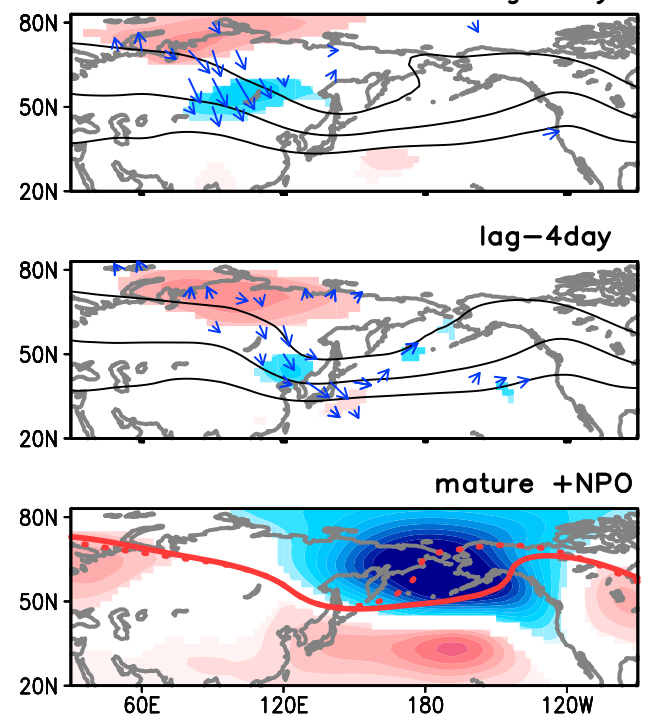

(b) $-\mathrm{NPO}$
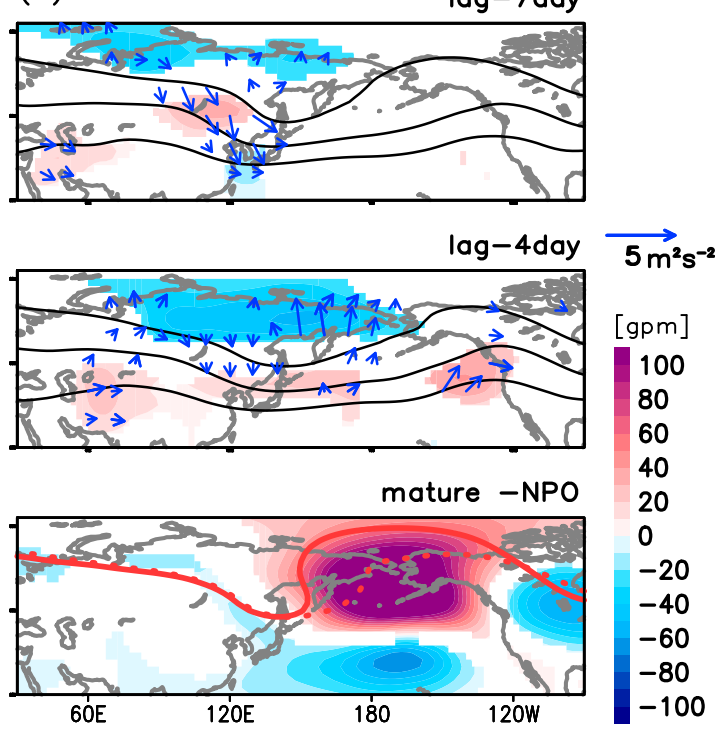

FIG. 7. Geopotential height anomalies (shading) and raw values (contour; 200-gpm intervals) at $500 \mathrm{hPa}$ during (a) + NPO and (b) - NPO events. The arrows denote wave activity flux significant at the $95 \%$ confidence level $\left(\mathrm{m}^{2} \mathrm{~s}^{-2}\right.$; magnitudes smaller than $0.5 \mathrm{~m}^{2} \mathrm{~s}^{-2}$ were omitted) (Takaya and Nakamura 2001). The bottom panels present the values for a mature period (i.e., average over onset to a lag of +4 days) of the NPO, in which the 5200gpm isoline is denoted in red for comparison with climatological references denoted by the dotted lines.

the thermal process leads to the growth and decay of the - NPO dominating the life cycle. The spatial distribution of the geopotential height tendency for the - NPO was consistent with that of the +NPO (Fig. 9). The estimated tendency produced by the three contributing factors reasonably captured the observed tendencies. As in +NPO, the southern branch of the -NPO originates from the temperature advection over the Korean Peninsula, lagging by -4 days. Then, the dipolar tendency associated with vorticity forcing accelerated the growth of meridional anomalies. The influence of diabatic heating was also initially pronounced around the Korean Peninsula, and then became dominant around the Bering Sea at a lag of -1 day,
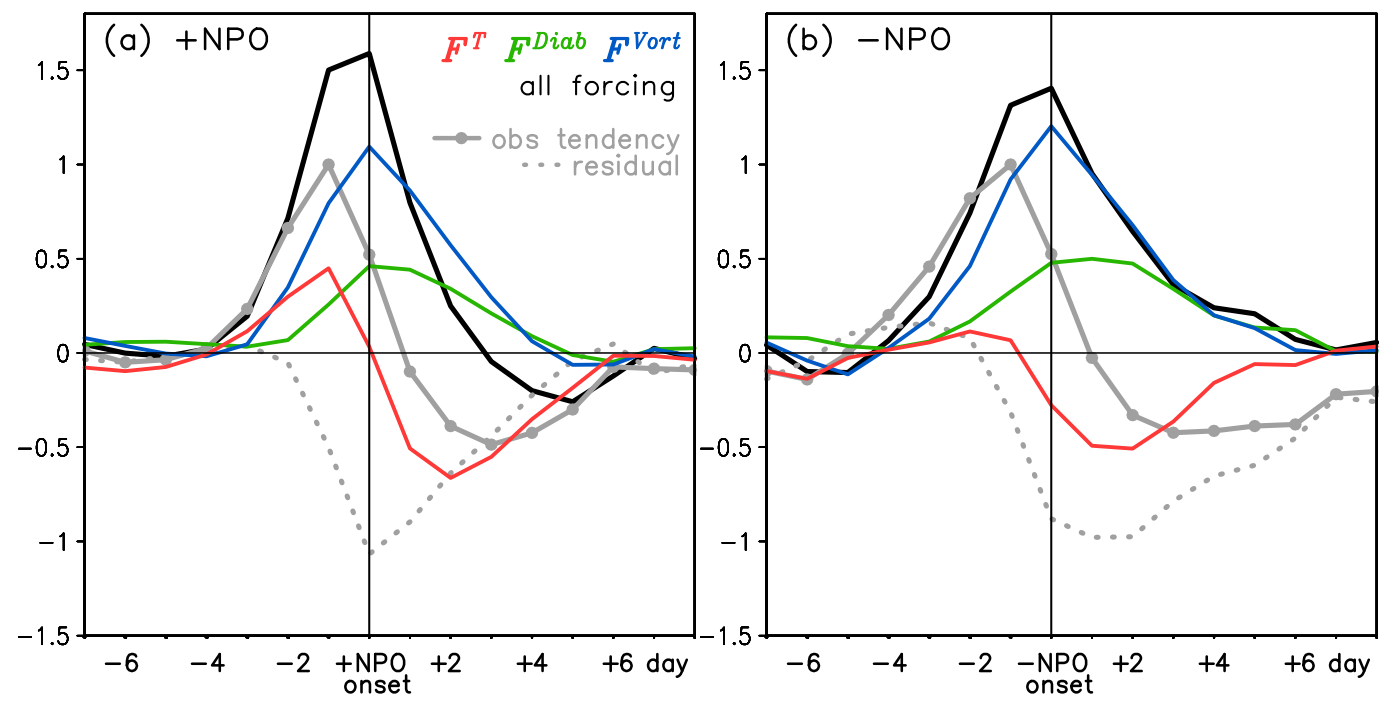

FIG. 8. Temporal evolution of the (a) +NPO and (b) - NPO events as revealed by a geopotential height tendency at $850 \mathrm{hPa}$ (gray line) and its drivers in terms of temperature fluxes $\left(F^{T}\right.$; red $)$, vorticity fluxes $\left(F^{\mathrm{Vort}}\right.$; blue), differential diabatic heating ( $F^{\text {Diab }}$; green), and their sum (black). The gray dotted line denotes residuals between the observed and estimated values. The values were normalized to the observed maximum tendency at a lag -1 day, which indicates that the observational peak is equal to one. 
-NPO lag-4day

(a) all forcing

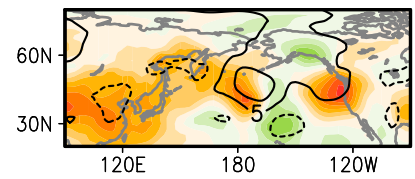

(b) $\boldsymbol{F}^{T}$

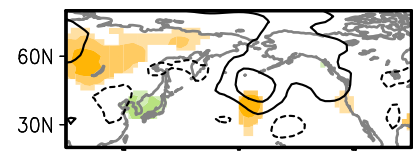

-NPO lag-2day

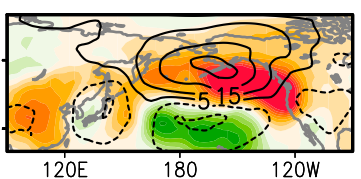

-NPO lag-1day

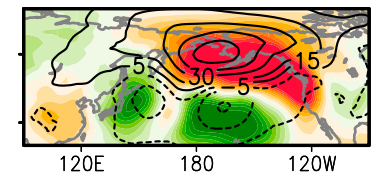

(c) $F^{\text {Vort }}$

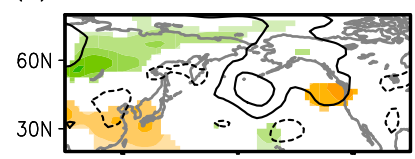

(d) $F^{D i a b}$

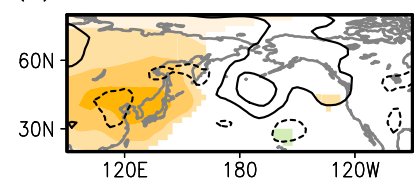

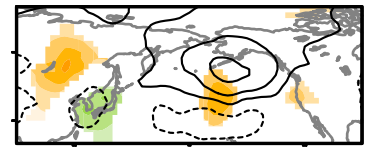
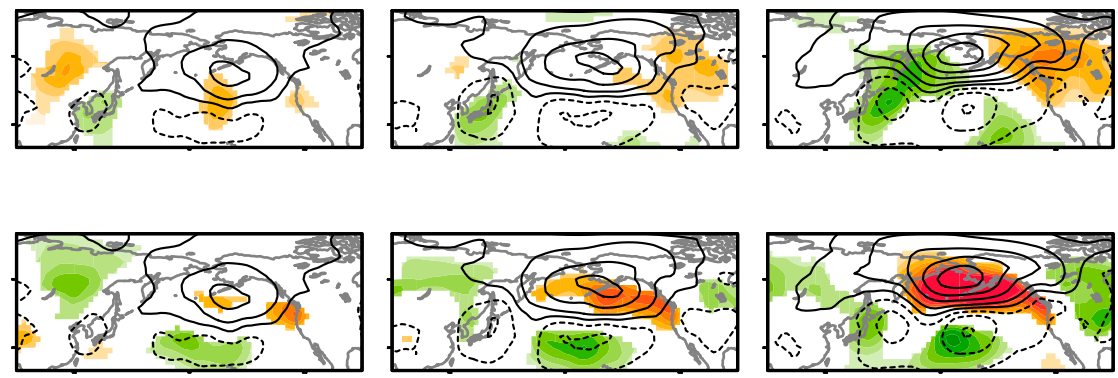

FIG. 9. Geopotential height tendency at $850 \mathrm{hPa}$ during -NPO events of observational data (contours) and estimated using the geopotential height tendency equation (shading) with (a) all forcing, (b) temperature fluxes $\left(F^{T}\right)$, (c) vorticity fluxes $\left(F^{\mathrm{Vort}}\right)$, and (d) differential diabatic heating $\left(F^{\text {Diab }}\right)$ terms. Contours are drawn at $\pm 5, \pm 15, \pm 30, \pm 45$, and \pm 60 gpm day $^{-1}$. In (b)-(d), only statistically significant values at the $95 \%$ confidence level are shaded.

assisting the growth of -NPO. A distinct characteristic was observed in terms of vorticity forcing, exhibiting a dipolar tendency farther to the east than that of +NPO. This presumably corresponds to the reduced East Asian trough, while a warm surge prevails over EA, as shown in Fig. $7 \mathrm{~b}$ (lag -4 days). As in +NPO, the influences of $F_{\text {stretch }}^{\text {Vort }}$ associated with the ageostrophic divergence were found to be considerable adjacent to the jet stream, contributing to the growth of the -NPO southern lobe (not shown).

\section{Summary and implications}

This study identified a pronounced lead-lag relationship between abnormal weather conditions over EA and NA in winter. A cold (warm) surge over EA had a tendency to be followed by a warm (cold) spell in NA approximately one week later. The dynamical mechanism underpinning this seesawing relationship of temperature extremes was elucidated based on budget analysis of the quasigeostrophic geopotential tendency equation. The influence of the three forcing terms, which include the differential temperature advection, vorticity advection, and differential diabatic heating, was quantitatively assessed. The results showed that an outbreak of cold or warm surge over EA is able to trigger NPO growth, leading to wide fluctuations of temperature in NA. Specifically, a severely cold (warm) air mass accumulating in EA triggers the growth of the +NPO (-NPO) as it disperses over the North Pacific, causing adjustments of thickness of atmospheric column. The vorticity flux by the perturbed upper tropospheric trough promoted the growth of the NPO and maintained anomalies against thermal damping following the onset of the NPO. The diabatic heating, secondarily generated by circulation changes, also positively contributed to the growth and maintenance of the NPO. These three forcing components steer the overall life cycle of the NPO. The results suggest that the intimate linkage between temperature fluctuations over EA and NA is an inherent characteristic of the climate system.

However, cold or warm surge events over EA do not always accompany the growth of the NPO. Although not shown, we found that antecedent conditions over the North Pacific with a substantially weaker (strong) Aleutian low hinders the growth of +NPO (-NPO). The growth of the cyclonic northern lobe of + NPO appeared to be favored by the strengthened cyclonic vorticity over the North Pacific. This is consistent with previous findings that NPO growth is partly influenced by the position and strength of the Aleutian low (Rogers 1981; Linkin and Nigam 2008). In the same vein, Dai and Tan (2019) discovered that the polarity of PNA event at a subseasonal time scale affects the NPO characteristics such as its amplitude and persistence, in conjunction with the seasonal condition of ENSO. We indeed observed weak but significant convective anomaly over the tropical Pacific preceding NPO events (not shown). The influence of the Pacific precondition may arise from the altered jet stream. In this study we only briefly addressed the influence of the 

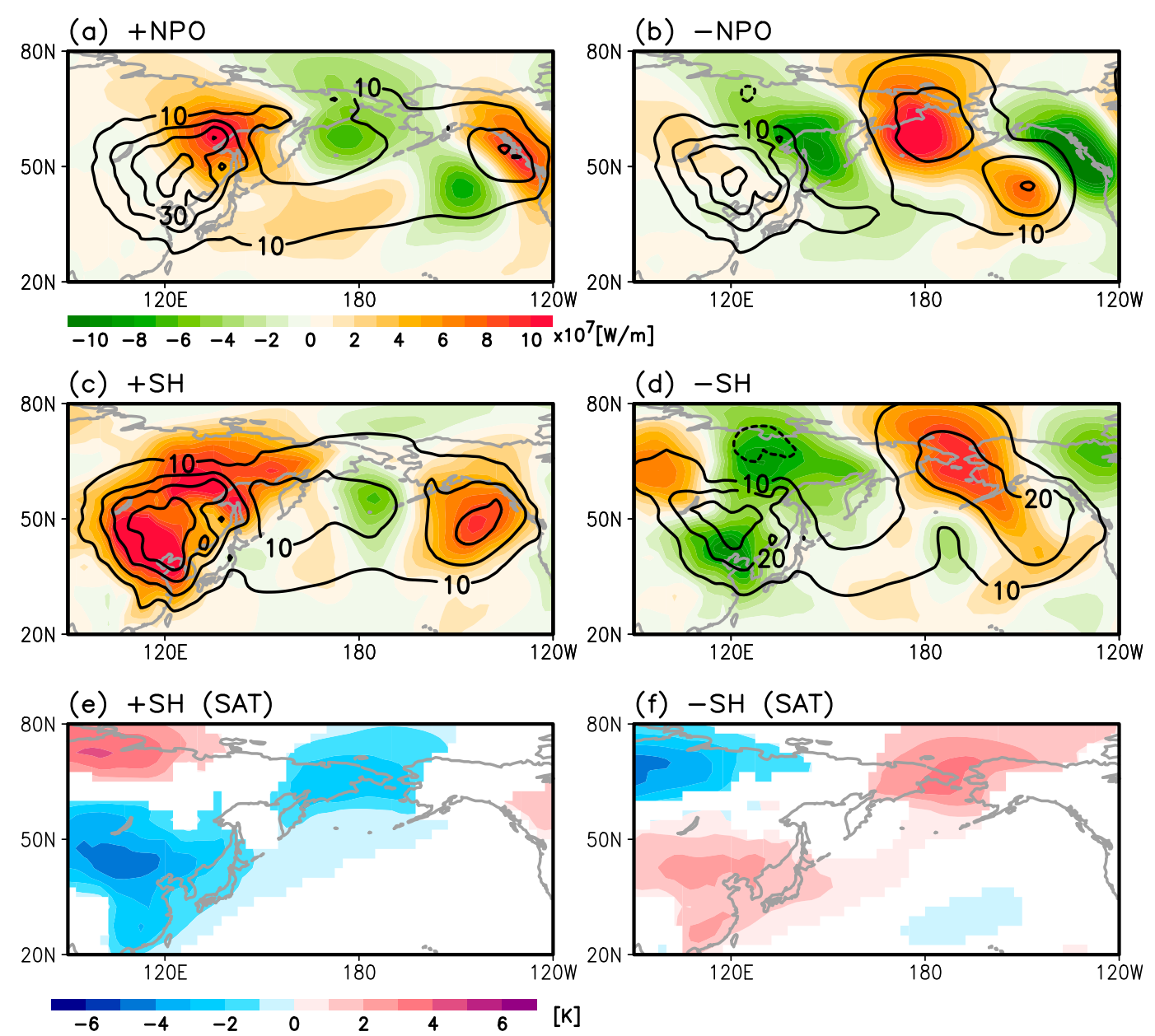

FIG. 10. Poleward sensible heat flux integrated from 1000 to $300 \mathrm{hPa}$ (contours) and associated anomalies (shading) averaged for the active period (i.e., from lag -3 to lag +6 days) of (a) + NPO and (b) - NPO events. (c),(d) As in (a) and (b), but for SH strengthening and weakening events, respectively, for the following 10 days from the onset. (e),(f) The corresponding surface air temperature anomalies during the SH events, in which only the statistically significant values at the $95 \%$ confidence level are shaded. The significance range was determined based on 1000 random resamplings. Poleward sensible heat flux is defined as $\left(C_{p} / g\right) \int_{1000 \mathrm{hPa}}^{300 \mathrm{hPa}} v^{*} T^{*} d p$, where $v^{*}$ and $T^{*}$ denote zonal anomalies in the meridional wind and temperature at a given latitude, respectively.

jet stream from the potential energy framework. Further analyses of kinetic energy could provide additional insight on the modulation of the Pacific precondition, as the NPO depends on the kinetic energy conversion from jet stream (Tanaka et al. 2016; Sung et al. 2020). The results of this study have two important implications for recurrent extremes, which are often attributed to Arctic warming, and for projected future climatic changes. Guan et al. (2020) discovered that anomalous anticyclonic circulation over Alaska, which resembles the - NPO, leads to warming in the Arctic on a subseasonal time scale, intensifying the "warm Arctic and cold continent" pattern over the NA sector. To understand this subseasonal warming in the Arctic accompanied by the growth of the NPO, it is helpful to look at the climatological wave structures around the North Pacific, which comprises the $\mathrm{SH}$ and Aleutian low in the lower troposphere and East Asian trough in the upper troposphere. The East Asian trough, which is placed to the west of the Aleutian low, exhibits a westward phase tilt of its cyclonic center with height. This allows the planetary-scale waves to efficiently transport sensible heat poleward (Higuchi and Shabbar 1991; Takaya and Nakamura 2013). During the mature phase of a +NPO, the East Asian trough expands to the east in conjunction with the dipolar geopotential height anomalies of the NPO (bottom panel in Fig. 7a), while shrinking to the west during a -NPO (Fig. 7b). Figures 10a and $10 \mathrm{~b}$ demonstrate that these structural changes in the planetary trough substantially modulate heat transport into the Arctic. In particular, when the trough shrinks (i.e., -NPO), there is a marked increase in meridional heat transport over the Arctic Pacific sector (Fig. 10b). Notably, similar changes were observed during a considerable disturbance of the $\mathrm{SH}$ intensity (Figs. 10c,d), with accompanying changes in the Arctic temperature (Figs. 10e,f). These processes may arise from planetaryscale waves responding to abrupt changes in atmospheric baroclinicity, because planetary-scale waves transport heat 
poleward more efficiently than synoptic-scale waves (Baggett and Lee 2015).

Our results suggest that the manner in which Arctic warming affects midlatitude daily weather may be far more complex than expected. Subseasonal warming over the Chukchi Sea and continental cooling ensuing from the growth of the - NPO suggest that Arctic warming on a subseasonal time scale is unlikely to cause cold extremes in NA. However, if a warm Arctic over the Kara Sea intensifies a cold surge in EA, as suggested in several studies (Mori et al. 2014, 2019; Luo et al. 2019) (also see lag -3 day in Fig. 2a), the resulting effect may reach across the Pacific through the "seesawing extremes" mechanism, leading to a warm spell in NA. These contrasting relationships between the Arctic and NA temperature anomalies implies that there is larger uncertainty associated with attributing NA temperature extremes to Arctic warming than it is usually expected. Regardless of the influence of Arctic warming, however, our results suggest an inherent dynamical linkage that facilitates opposing temperature extremes under a warming climate. This indicates that a projected shift in mean temperature may not necessarily reduce the risk of cold extremes provided the continuing operation of the planetary seesaw.

Acknowledgments. This research was supported by a National Research Foundation of Korea (NRF) grant funded by the Korean government (MSIT) (NRF-2018R1A5A1024958). Author Sung was supported by NRF-2018R1D1A1B07044112. Author Yoo was supported by NRF-2019R1C1C1003161.

\section{REFERENCES}

Baggett, C., and S. Lee, 2015: Arctic warming induced by tropically forced tapping of available potential energy and the role of the planetary-scale waves. J. Atmos. Sci., 72, 1562-1568, https:// doi.org/10.1175/JAS-D-14-0334.1.

Blackport, R., J. A. Screen, K. van der Wiel, and R. Bintanja, 2019: Minimal influence of reduced Arctic sea ice on coincident cold winters in mid-latitudes. Nat. Climate Change, 9, 697-704, https://doi.org/10.1038/s41558-019-0551-4.

Cohen, J., K. Pfeiffer, and J. A. Francis, 2018: Warm Arctic episodes linked with increased frequency of extreme winter weather in the United States. Nat. Commun., 9, 869, https:// doi.org/10.1038/s41467-018-02992-9.

— , and Coauthors, 2020: Divergent consensuses on Arctic amplification influence on midlatitude severe winter weather. Nat. Climate Change, 10, 20-29, https://doi.org/10.1038/s41558-019-0662-y.

Dai, Y., and B. Tan, 2019: Two types of the western Pacific pattern, their climate impacts, and the ENSO modulations. J. Climate, 32, 823-841, https://doi.org/10.1175/JCLI-D-17-0618.1.

Di Lorenzo, E., and N. Mantua, 2016: Multi-year persistence of the 2014/15 North Pacific marine heatwave. Nat. Climate Change, 6, 1042-1047, https://doi.org/10.1038/nclimate3082.

Feldstein, S. B., 2000: The timescale, power spectra, and climate noise properties of teleconnection patterns. J. Climate, 13, 4430-4440, https://doi.org/10.1175/1520-0442(2000)013<4430: TTPSAC $>2.0 . \mathrm{CO} ; 2$.

— Nonlinear and Stochastic Climate Dynamics, C. L. E. Franzke and T. J. O'Kane, Eds., Cambridge University Press, 54-104.

Francis, J. A., 2017: Why are Arctic linkages to extreme weather still up in the air? Bull. Amer. Meteor. Soc., 98, 2551-2557, https://doi.org/10.1175/BAMS-D-17-0006.1.
Furtado, J. C., E. Di Lorenzo, B. T. Anderson, and N. Schneider, 2012: Linkages between the North Pacific Oscillation and central tropical Pacific SSTs at low frequencies. Climate Dyn., 39, 2833-2846, https://doi.org/10.1007/s00382-011-1245-4.

Gill, A. E., 1982: Atmosphere-Ocean Dynamics. Academic Press, 662 pp.

Guan, W., X. Jiang, X. Ren, G. Chen, and Q. Ding, 2020: Role of atmospheric variability in driving the "warm-Arctic, coldcontinent" pattern over the North America sector and sea ice variability over the Chukchi-Bering Sea. Geophys. Res. Lett., 47, e2020GL088599, https://doi.org/10.1029/2020GL088599.

Guirguis, K., A. Gershunov, R. Schwartz, and S. Bennett, 2011: Recent warm and cold daily winter temperature extremes in the Northern Hemisphere. Geophys. Res. Lett., 38, L17701, https://doi.org/10.1029/2011GL048762.

Hartmann, D. L., 2014: Pacific sea surface temperature and the winter of 2014. Geophys. Res. Lett., 42, 1894-1902, https:// doi.org/10.1002/2015GL063083.

Higuchi, K., and A. Shabbar, 1991: Interannual variability of the January tropospheric meridional eddy sensible heat transport in the northern latitudes. J. Meteor. Soc. Japan, 69, 459-472, https://doi.org/10.2151/jmsj1965.69.4_459.

Holton, J. R., 2004: An Introduction to Dynamic Meteorology. Academic Press, 531 pp.

Honda, M., J. Inoue, and S. Yamane, 2009: Influence of low Arctic seaice minima on anomalously cold Eurasian winters. Geophys. Res. Lett., 36, L08707, https://doi.org/10.1029/2008GL037079.

Hoskins, B. J., M. E. McIntyre, and A. W. Robertson, 1985: On the use and significance of isentropic potential vorticity maps. Quart. J. Roy. Meteor. Soc., 111, 877-946, https://doi.org/ 10.1002/qj.49711147002.

Hwang, J.-Y., P. Martineau, S.-W. Son, T. Miyasaka, and H. Nakamura, 2020: The role of transient eddies in North Pacific blocking formation and its seasonality. J. Atmos. Sci., 77, 2453-2470, https:// doi.org/10.1175/JAS-D-20-0011.1.

Johnson, N. C., S.-P. Xie, Y. Kosaka, and X. Li, 2018: Increasing occurrence of cold and warm extremes during the recent global warming slowdown. Nat. Commun., 9, 1724, https:// doi.org/10.1038/s41467-018-04040-y.

Joung, C. H., and M. H. Hitchman, 1982: On the role of successive downstream development in East Asian polar air outbreaks. Mon. Wea. Rev., 110, 1224-1237, https://doi.org/10.1175/15200493(1982)110<1224:OTROSD > 2.0.CO;2.

Kim, M., C. Yoo, M.-K. Sung, and S. Lee, 2021: Classification of wintertime atmospheric teleconnection patterns in the Northern Hemisphere. J. Climate, 34, 1847-1861, https://doi.org/10.1175/ JCLI-D-20-0339.1.

Kobayashi, S., and Coauthors, 2015: The JRA-55 Reanalysis: General specifications and basic characteristics. J. Meteor. Soc. Japan, 93, 5-48, https://doi.org/10.2151/jmsj.2015-001.

Kug, J.-S., J.-H. Jeong, Y.-S. Jang, B.-M. Kim, C. K. Folland, S.-K. Min, and S.-W. Son, 2015: Two distinct influences of Arctic warming on cold winters over North America and East Asia. Nat. Geosci., 8, 759-762, https://doi.org/10.1038/ngeo2517.

Lau, N. C., and E. O. Holopainen, 1984: Transient eddy forcing of the time-mean flow as identified by geopotential tendencies. J. Atmos. Sci., 41, 313-328, https://doi.org/10.1175/1520-0469(1984)041<0313: TEFOTT $>2.0 . \mathrm{CO} ; 2$.

Lee, M.-Y., C.-C. Hong, and H.-H. Hsu, 2015: Compounding effects of warm sea surface temperature and reduced sea ice on the extreme circulation over the extratropical North Pacific and North America during the 2013-2014 boreal winter. Geophys. Res. Lett., 42, 1612-1618, https://doi.org/10.1002/ 2014GL062956. 
Lin, H., 2018: Predicting the dominant patterns of subseasonal variability of wintertime surface air temperature in extratropical Northern Hemisphere. Geophys. Res. Lett., 45, 43814389, https://doi.org/10.1029/2018GL077509.

Linkin, M. E., and S. Nigam, 2008: The North Pacific oscillationwest Pacific teleconnection pattern: Mature-phase structure and winter impacts. J. Climate, 21, 1979-1997, https://doi.org/ 10.1175/2007JCLI2048.1.

Luo, D., X. Chen, J. Overland, I. Simmonds, Y. Wu, and P. Zhang, 2019: Weakened potential vorticity barrier linked to recent winter Arctic sea ice loss and midlatitude cold extremes. J. Climate, 32, 4235-4261, https://doi.org/10.1175/JCLI-D-180449.1.

Ma, S., C. Zhu, B. Liu, T. Zhou, Y. Ding, and Y. J. Orsolini, 2018: Polarized response of East Asian winter temperature extremes in the era of Arctic warming. J. Climate, 31, 5543-5557, https://doi.org/10.1175/JCLI-D-17-0463.1.

McCusker, K. E., J. C. Fyfe, and M. Sigmond, 2016: Twenty-five winters of unexpected Eurasian cooling unlikely due to Arctic sea-ice loss. Nat. Geosci., 9, 838-842, https://doi.org/10.1038/ ngeo 2820 .

Morak, S., G. C. Hegerl, and N. Christidis, 2013: Detectable changes in the frequency of temperature extremes. J. Climate, 26, 1561-1574, https://doi.org/10.1175/JCLI-D-11-00678.1.

Mori, M., M. Watanabe, H. Shiogama, J. Inoue, and M. Kimoto, 2014: Robust Arctic sea-ice influence on the frequent Eurasian cold winters in past decades. Nat. Geosci., 7, 869-873, https:// doi.org/10.1038/ngeo2277.

- Y. Yosaka, M. Watanabe, H. Nakamura, and M. Kimoto, 2019: A reconciled estimate of the influence of Arctic sea-ice loss on recent Eurasian cooling. Nat. Climate Change, 9, 123129, https://doi.org/10.1038/s41558-018-0379-3.

Nakamura, H., T. Miyasaka, Y. Kosaka, K. Takaya, and M. Honda, 2010: Northern Hemisphere extratropical tropospheric planetary waves and their low-frequency variability: Their vertical structure and interaction with transient eddies and surface thermal contrasts. Climate Dynamics: Why Does Climate Vary?, Geophys. Monogr.,Vol. 189, Amer. Geophys. Union, 149-179.

NOAA National Climate Report, 2020: National Centers for Environmental Information, State of the Climate: National Climate Report. Accessed 2 February 2020, https://www. ncdc.noaa.gov/sotc/national/201702.

Pak, G., Y.-H. Park, F. Vivier, Y.-O. Kwon, and K.-I. Chang, 2014: Regime-dependent nonstationary relationship between the East Asian winter monsoon and north Pacific oscillation. J. Climate, 27, 8185-8204, https://doi.org/10.1175/JCLI-D-13-00500.1.

Palmer, T., 2014: Record-breaking winters and global climate change. Science, 344, 803-804, https://doi.org/10.1126/science.1255147.

Rogers, J., 1981: The North Pacific oscillation. Int. J. Climatol., 1, 39-57, https://doi.org/10.1002/joc.3370010106.

Song, L., L. Wang, W. Chen, and Y. Zhang, 2016: Intraseasonal variation of the strength of the East Asian trough and its climatic impacts in boreal winter. J. Climate, 29, 2557-2577, https://doi.org/10.1175/JCLI-D-14-00834.1.

Sung, M.-K., G.-H. Lim, and J.-S. Kug, 2010: Phase asymmetric downstream development of the North Atlantic Oscillation and its impact on the East Asian winter monsoon. J. Geophys. Res., 115, D09105, https://doi.org/10.1029/2009JD013153.

- H.-Y. Jang, B.-M. Kim, S.-W. Yeh, Y.-S. Choi, and C. Yoo, 2019: Tropical influence on the North Pacific Oscillation drives winter extremes in North America. Nat. Climate Change, 9, 413-418, https://doi.org/10.1038/s41558-019-0461-5.

_ C. Yoo, S.-W. Yeh, Y. Kosaka, and S.-I. An, 2020: Characteristics of the North Pacific Oscillation in CMIP5 models in relation to atmospheric mean states. J. Climate, 33, 3809-3825, https:/doi.org/ 10.1175/JCLI-D-19-0446.1.

Takaya, K., and H. Nakamura, 2001: A formulation of a phaseindependent wave-activity flux for stationary and migratory quasigeostrophic eddies on a zonally varying basic flow. J. Atmos. Sci., 58, 608-627, https://doi.org/10.1175/1520-0469(2001)058<0608: AFOAPI $>2.0 . \mathrm{CO} ; 2$.

, and - 2005: Mechanisms of intraseasonal amplification of the cold Siberian high. J. Atmos. Sci., 62, 4423-4440, https:// doi.org/10.1175/JAS3629.1.

$\longrightarrow$, and — 2013: Interannual variability of the East Asian winter monsoon and related modulations of the planetary waves. J. Climate, 26, 9445-9461, https://doi.org/10.1175/JCLID-12-00842.1.

Tanaka, S., K. Nishii, and H. Nakamura, 2016: Vertical structure and energetics of the western Pacific teleconnection pattern. J. Climate, 29, 6597-6616, https://doi.org/10.1175/JCLI-D-150549.1.

Walker, G. T., and E. W. Bliss, 1932: World weather V. Mem. Roy. Meteor. Soc., 4, 54-84.

Wallace, J. M., and D. S. Gutzler, 1981: Teleconnections in the geopotential height field during the Northern Hemisphere winter. Mon. Wea. Rev., 109, 784-812, https://doi.org/10.1175/ 1520-0493(1981)109<0784:TITGHF>2.0.CO;2.

Wang, L., and W. Chen, 2014: The East Asian winter monsoon: Re-amplification in the mid-2000s. Chin. Sci. Bull., 59, 430436, https://doi.org/10.1007/s11434-013-0029-0.

,-- , and R. Huang, 2007: Changes in the variability of North Pacific Oscillation around 1975/1976 and its relationship with East Asian winter climate. J. Geophys. Res., 112, D11110, https://doi.org/10.1029/2006JD008054.

-, W. Zhou, and R. Huang, 2009: Interannual variations of East Asian trough axis at $500 \mathrm{hPa}$ and its association with the East Asian winter monsoon pathway. J. Climate, 22, 600-614, https://doi.org/10.1175/2008JCLI2295.1.

Watson, P. A. G., A. Weisheimer, J. R. Knight, and T. N. Palmer, 2016: The role of the tropical west Pacific in the extreme Northern Hemisphere winter of 2013/2014. J. Geophys. Res., 121, 1698-1714, https://doi.org/10.1002/2015JD024048.

Welch, A. B. L., 1938: The significance of the difference between two means when the population variances are unequal. Biometrika, 29, 350-362, https://doi.org/10.2307/2332010.

Wolter, K., M. Hoerling, J. K. Eischeid, G. J. van Oldenborgh, X.-W. Quan, J. E. Walsh, T. N. Chase, and R. M. Dole, 2015: How unusual was the cold winter of 2013/14 in the upper Midwest? [in "Explaining Extreme Events of 2014 from a Climate Perspective"']. Bull. Amer. Meteor. Soc., 96 (12), S10S14, https://doi.org/10.1175/BAMS-D-15-00126.1. 